Cuadernos de Trabajo Social

ISSN: 0214-0314

http://dx.doi.org/10.5209/CUTS.53959

\title{
Repensar la ética en Trabajo Social desde una perspectiva de género
}

\author{
Belén Agrela Romero ${ }^{1}$; Camino Gutiérrez Casal $^{2}$; Teresa Fernández Contreras ${ }^{3}$
}

Recibido: 20 de octubre de 2016 / Aceptado: 28 de noviembre de 2016 / Disponible on line: 10 de enero de 2017

Resumen. El objetivo del artículo es reflexionar sobre los dilemas éticos en Trabajo Social desde un enfoque de género, especialmente cuando intervenimos con mujeres. Mediante una investigación cualitativa hemos analizado el discurso de profesionales para identificar la manera en la que la dimensión ética y el género atraviesan las formas de pensar e intervenir. Repensar la ética desde una perspectiva de género es central para comprender la manera en la que construimos el Trabajo Social teórica y metodológicamente.

Palabras clave: Trabajo Social; género; ética; ejercicio profesional; emociones.

\section{[en] Rethinking ethics in Social Work from a gender perspective}

\begin{abstract}
The aim of this article is to reflect on ethical dilemmas in social work with a focus on gender, especially with regard to interventions with women. We carried out a qualitative investigation to analyze professional discourse in order to identify the way in which the ethical dimension and gender cut across ways of thinking and intervening. Rethinking ethics from this perspective is central to understanding how we construct social work, both theoretically and methodologically.
\end{abstract}

Keywords: Social Work; gender; ethics; professional practice; emotions.

Sumario: Introducción. 1. Metodología. 2. Resultados. 3. Debate abierto sobre los dilemas éticos, el género y las emociones en Trabajo Social. 4. Referencias bibliográficas.

Cómo citar: Agrela Romero, B.; Gutiérrez Casal, C. \& Fernández Contreras, T. (2017) Repensar la ética en Trabajo Social desde una perspectiva de género, en Cuad. trab. soc. 30(1), 51-64.

\section{Introducción}

Este artículo analiza los dilemas éticos en Trabajo Social en su relación con la dimensión de género reparando en cómo hemos aprendido a ser trabajadoras sociales, a partir del modelo de género tradicional femenino de «cuidadoras sociales», y en cómo condiciona que, mayoritariamente, las usuarias sean cada vez más mujeres (Lima, 2014; Red Europea de Lucha contra la Pobreza y la Exclusión Social, 2015). Ahondamos en las dificultades y las contradicciones que surgen cuando abordamos los temas que refieren a las situaciones de desigualdad de las mujeres. De manera especial nos ocupamos de las disociaciones que, a menudo, establecemos entre la dimensión cognitiva con la que mira-

\footnotetext{
Universidad de Jaén, España

E-mail: bagrela@ujaen.es

2 Ayuntamiento de Granada, España

E-mail: caminoguca@gmail.com

3 Universidad de Jaén, España

E-mail: teresa.fdez.contreras@gmail.com
} 
mos y analizamos la situación de unas determinadas usuarias, así como las respuestas con las que intervenimos después en dicha situación. Nos referimos al conflicto que se produce cuando hay un choque entre los valores personales y los deberes profesionales (Salcedo, 2015) y los casos en los que se «han de incumplir las obligaciones que fija la profesionalidad, o bien (se) ha de transgredir principios firmemente sostenidos. Se produce, entonces, una quiebra en el propio sentido de la identidad, dividiéndose en una parte personal y otra profesional» (Salcedo, 2015, p. 23). Estas discordancias éticas en ocasiones pueden dar lugar al autocuestionamiento de nuestro trabajo, de lo que significa «ser buenas profesionales»; y de cómo establecer un equilibrio entre mis convicciones y lo que puedo o debo hacer cuando intervengo con mujeres. En la investigación realizada se pone de manifiesto que las y los trabajadores sociales enfatizan que, habitualmente, en situaciones complejas con numerosas aristas morales y emocionales que refieren a las mujeres, se ven desprovistos/as de una «caja de herramientas éticas» para la intervención. Ello responde, en gran medida, al valor residual que se le concede a la dimensión ética en la formación y ejercicio diario del Trabajo Social, pero también, al escaso análisis que interrelaciona la ética con el género (Dominelli y MacLeod, 1999; Amorós, 2002; Perrot, 2008). Proponemos reflexionar sobre cómo, desde nuestra posición de género, subjetiva, y en tanto que sujetos (profesionales) «encarnados», no somos ajenos/as a las múltiples contradicciones y emociones que atraviesan la cuestión ética en Trabajo Social. Estas dimensiones han sido tradicionalmente esquivadas $\mathrm{y}$, sin embargo, son centrales para comprender la manera en la que construimos nuestro trabajo y acometemos las intervenciones teórica y metodológicamente.

\section{Los dilemas éticos en la intervención des- de la perspectiva del Trabajo Social}

El Trabajo Social tiene por objeto profesional la intervención en unas dimensiones fundamentales de las personas, propiciando la actuación más conveniente para mejorar sus condiciones de vida, posibilitando la atención, el cuidado y la defensa de los grupos más vulnerables (Banks, 2006). Dado que no suele haber un único camino para tal finalidad, resulta inevitable que surjan problemas éticos con respecto a cuál es el proceder más pertinente. A menudo nos encontramos con una situación-necesidad que exige tomar decisiones sobre varias alternativas posibles, no siempre deseables, sin estar claro cuál elección es la correcta (Banks, 2006).

$\mathrm{Al}$ (pre)ocuparnos por responder de la forma más conveniente para resolver una necesidad, inevitablemente emerge la toma de conciencia de la dimensión ética en Trabajo Social. Es una parte fundamental de la práctica profesional que implica, antes, durante y después, la toma de decisiones y acciones, a partir de la comprensión de la complejidad de los problemas sociales (Reamer, 1998). Dicha actuación, que significa un cambio en la realidad-circunstancias de la persona, tiene una intencionalidad y unos objetivos de lo que se quiere conseguir modificar y hacia dónde orientar su futuro, a corto y largo plazo. Esto implica unas responsabilidades morales con respecto a las consecuencias que tendrá para esa persona y su contexto social próximo, pero también, con respecto a nuestro trabajo profesional y hacia nosotros y nosotras mismas. La actividad profesional se realiza según los principios con los que el Trabajo Social se ha comprometido con la sociedad (Salcedo, 2015). En consecuencia nos preguntamos ¿qué ocurre cuando entran en contradicción los valores profesionales con nuestros valores y convicciones personales?

Diariamente nos encontramos con situaciones personales y familiares donde la complejidad de cada caso merece de una atención personalizada y responsable. Existen unas coordenadas generales de referencia con respecto a problemas y procesos de vulnerabilidad que son compartidos por distintas personas en una misma situación. De acuerdo con el principio de individualización, cada caso es particular y supone unos impactos diferentes, según la coyuntura de cada persona. Los problemas suceden en un contexto determi- 
nado, en un momento histórico vital específico, bajo unas lógicas propias que lo generan y explican que desencadenan unas dificultades-necesidades que obran de forma privativa. Cada situación requiere una implicación y un análisis concretos, que en ocasiones entran en conflicto con la universalidad con la que se espera que actuemos en nuestro ejercicio cotidiano de la profesión. Asimismo, es frecuente que nos asalten los dilemas cuando, queriendo aplicar el principio del respeto al derecho de autodeterminación y buscando acatar las decisiones que toma una mujer con respecto a su situación, dicha actuación nos produce tensiones porque de sus decisiones se derive un peligro o una situación negativa para esta mujer o para terceras personas; o porque profesionalmente valoramos que no es lo que más le conviene a la usuaria. Ante esto ¿de qué manera manejo mis responsabilidad profesional y ética?

Cuando se plantean situaciones como estas de difícil abordaje, dependiendo de la resolución escogida se podrá suscitar un gran descontento e insatisfacción tanto entre las personas con las que intervenimos como entre las y los mismos profesionales del Trabajo Social (Ballestero, Úriz y Viscarret, 2012). Los dilemas son incómodos; crean gran angustia y desasosiego en las trabajadoras y los trabajadores sociales, pues conllevan un cierto «dispendio moral» (Úriz, 2013, p. 194). Irremediablemente existe una carga emocional y afectiva que hace patente las maneras en las que nos implicamos en nuestro trabajo. El «síndrome del queme profesional» contribuye de alguna forma a complejizar la dimensión ética de nuestras decisiones en la intervención social, yendo en contra de nuestro deterioro de imagen y (auto)valoración social como profesionales de la ayuda social (Rodríguez, 2014, p. 58).

La deontología profesional nos sirve para establecer el marco de actuación y los criterios sobre los que fundamentamos cómo proceder de acuerdo con "cómo deberían ser las cosas», y cuál es la estrategia apropiada para actuar. Son los axiomas con los que el y la profesional decidirán su ejercicio y juzgarán tanto su propia conducta como la de sus com- pañeras y compañeros. Los códigos son distintivos en el Trabajo Social (Lima, 2013), marco de referencia de los deberes universales exigibles en el desempeño de nuestra actividad, que contribuyen al aumento del valor, poder y reconocimiento social de determinadas profesiones. Están definidos y legitimados por la confianza y el compromiso que se espera con el bienestar de la sociedad. Estos códigos debieran servirnos para tener unas pautas y reglas sobre cómo actuar de un modo íntegro, profesional y coherente moralmente. Sin embargo, manejar los dilemas que derivan de la intervención no es una tarea liviana de dirimir, dado que existen dimensiones personales, profesionales e institucionales que condicionan los posibles caminos o elecciones para la obtención del bienestar. Muestra de ello, según la investigación de Ballestero, Úriz y Vicarret (2012), es que alrededor del 82 por ciento de las y los profesionales de Trabajo Social reconocen haberse enfrentado a algún dilema ético en su ejercicio profesional, donde junto a los factores intrínsecos y extrínsecos a la intervención, los condicionantes vinculados al tipo de relación establecida con los usuarios y las usuarias tienen una influencia significativa. Precisamente a este aspecto nos referimos en este artículo, considerando las vinculaciones entre la ética y el género en la relación entre el profesional o la profesional y la usuaria.

\section{Metodología}

Los hallazgos que presentamos provienen de trabajos de campo realizados en investigaciones acometidas por las autoras en varios momentos, entre los años 2015 y 2016. Desde un enfoque cualitativo, hemos querido conocer los discursos y las representaciones sobre cómo la perspectiva de género atraviesa los dilemas éticos en la intervención con mujeres. Entrevistamos a 21 profesionales de Trabajo Social, mujeres y hombres involucrados en los programas de atención directa a las mujeres, tanto en los Servicios Sociales públicos como concertados y privados. Con este muestreo de tipo intencional quisimos dar cuenta de la re- 
Cuadro 1. Perfil de las entrevistas (2015-2016)

\begin{tabular}{|l|l|l|l|c|}
\hline \multicolumn{1}{|c|}{ Sexo } & Provincia & Centro de trabajo & \multicolumn{1}{|c|}{ Ámbito de intervención } & Código \\
\hline Mujer & Granada & Público & Barriadas actuación preferente & E1 \\
Hombre & Granada & Privado & Pobreza y exclusión social & E2 \\
Hombre & Granada & Privado (ONG) & Inmigración & E3 \\
Mujer & Granada & Público & Violencia de género & E4 \\
Mujer & Granada & Privado-Público & Colegio profesional & E5 \\
Mujer & Granada & Público & Área mujer & E6 \\
Mujer & Granada & Público & Mediación menores & E7 \\
Mujer & Granada & Público & Dependencia & E8 \\
Mujer & Granada & Público & Prisiones & E9 \\
Hombre & Jaén & Público & Familia & E10 \\
Mujer & Jaén & Público & Tercera edad & E11 \\
Mujer & Jaén & Concertado & Tercera edad & E12 \\
Hombre & Jaén & Privado & Medidas en medio abierto & E13 \\
Mujer & Jaén & Público & Área mujer, empleo & E14 \\
Mujer & Jaén & Privado & Inmigración & E15 \\
Mujer & Jaén & Público & Violencia de género & E16 \\
Hombre & Jaén & Concertado & Discapacidad & E17 \\
Hombre & Almería & Privado (ONG) & Inmigración & E18 \\
Mujer & Almería & Público & Discapacidad & E19 \\
Hombre & Almería & Público & Familia & E20 \\
Mujer & Almería & Privado & Dependencia & E21 \\
\hline
\end{tabular}

presentatividad de escenarios desde donde se ejerce el Trabajo Social. Las tareas de contactación se hicieron en su mayoría directamente, a partir de las conexiones que hemos establecido desde nuestros espacios laborales. A su vez, nos servimos de la técnica «bola de nieve» para acceder a informantes clave que fueron surgiendo en las entrevistas.

La mayor parte de las entrevistadas han sido mujeres, con un rango de edad entre $36 \mathrm{y}$ 50 años, con más de 10 años de experiencia profesional de las provincias de Granada, Jaén y Almería (véase Cuadro 1). Nos interesaba poder contar con los discursos y las valoraciones de profesionales que tuvieran un largo recorrido en el ejercicio del Trabajo Social para que sus reflexiones las sustentaran sus conocimientos epistemológicos y empíricos sobre sus prácticas con mujeres a lo largo de su trayectoria profesional (no necesariamente las referidas al presente y en el contexto de su posición actual). Quisimos dialogar con quienes, a partir de su dilatada experiencia profesional, pudieran discursar sobre sus entendimientos ideológicos y sus prácticas de actuación en relación a cómo piensan en si mismas las mujeres y desde la ética como sujetos de intervención en Trabajo Social ${ }^{4}$.

El instrumento fundamental para la producción de datos ha sido la entrevista en profundidad (para posibilitar la creación del discurso y las representaciones colectivas y personalizadas (Ortí, 2007) del profesional en relación a la dimensión ética; estos datos discursivos del lenguaje nos han permitido interpretar en su contexto los significados y el sentido otorgado a la ética en relación con la dimensión de género) y semiestructurada (para posibilitar el diálogo abierto a determinadas cuestiones específicas sobre la ética

No negamos que hubiera sido también muy interesante contrastar estos discursos con los elaborados por profesionales con menos experiencia laboral, indagando además en el modo en el que la dimensión y el discurso oficial institucional se impregnan, en sus formas de comprender cómo se analiza la situación de las mujeres y su relación con la ética. Queda pendiente para otra investigación futura. 
articuladas con la posición laboral, la institución a la que pertenece, su modo de participación en los programas que desarrolla y el tipo de necesidades o problemas a los que da respuesta). El guión se ha diseñado específicamente para el estudio, organizado en siete ámbitos relativos a: la institución donde trabaja; experiencia laboral; el trabajo que desempeña en el centro; el impacto de la crisis económica tanto en los usuarios y las usuarias como en los programas; los dilemas éticos en la intervención; el género en los dilemas éticos; y la gestión de los dilemas éticos ${ }^{5}$. También hemos utilizado algunas técnicas cualitativas de carácter etnográfico, como el diario de campo de las autoras que trabajamos el género, la ética y el Trabajo Social en los Servicios Sociales, la investigación y la docencia.

Parte de los resultados obtenidos los hemos organizado para este texto en tres macro-categorías de análisis de contenido: 1) los dilemas sobre el autocuestionamiento profesional y el género; 2) los condicionantes en el ejercicio profesional con mujeres; y 3 ) los dilemas éticos sobre el ser y el deber ser.

\section{Resultados}

\subsection{Los dilemas sobre el autocuestiona- miento profesional y el género}

Está ampliamente constatado que, en la historia del Trabajo Social la feminización forma parte de nuestra profesión, de nuestro ámbito académico y del perfil de la población atendida (Báñez, 1997; Dominelli y McLeod, 1999; Fombuena, 2006; Morales, 2010; Lorente, 2013). No obstante, la manera en la que la dimensión de género impregna nuestro ejercicio profesional está menos explorada, y concretamente, las dimensiones éticas y las implicaciones emocionales de género que nos (auto)cuestionan en relación a cómo ser «un o una buena profesional». Estas exigencias a menudo tienen que ver con cómo hemos aprendido a ejercer la profesión, partiendo de nuestra condición de género, y cómo ello concreta la manera en que me relaciono (o debiera relacionarme) con las personas usuarias (en su mayoría, mujeres). Son habituales expresiones como: "a menudo me cuestiono constantemente» (E3); «no sé bien qué opción es la mejor y me genera mil dudas» (E2); «dudo mucho sobre cómo ser buena profesional y no morir en el intento» (E19).

Este cuestionamiento influye en aspectos como mi forma de entender un problema, desde dónde me posiciono, hasta dónde me implico, los procesos de transferencia que a menudo me asaltan, o la conciliación entre mis valores personales y los de la institución. Son juicios morales sobre uno o una misma, como trabajador o trabajadora social, que frecuentemente se ignoran, silencian o reprimen en el espacio profesional y académico; que no traspasan el reducto personal o la red próxima de relaciones.

En la gestión diaria no hay tiempo para pararte a pensar cómo haces tu trabajo porque tienes muchos expedientes en cola y problemas urgentes que resolver (...) Al final, cuando tienes dilemas importantes sobre qué hacer, se lo comentas a tus colegas más íntimas, con las que mejor te llevas. Si puedes tratarlo con tu jefa, pues lo haces (...) Los temas éticos se tratan poco, los resuelves como puedes y para adelante. Pero se te van acumulando, te van haciendo mella y llega un día en que tienes una carga muy pesada, que está ahí y te ha ido erosionando (E1).

A pesar de la invisibilidad de este autocuestionamiento y autoexigencia, todas las personas entrevistadas los refieren como elementos clave para explicar muchas de las (in)satisfacciones profesionales habituales en el Trabajo Social: «creemos que vamos a poder solucionar la situación de muchas mujeres, pero luego te das cuenta de que eres solo una tirita en una herida abierta (...) Y reconocerlo genera mucha insatisfacción» (E20).

\footnotetext{
La mayor parte de las entrevistas pudieron ser grabadas y transcriptas posteriormente. Así mismo, de forma previa a la realización de la entrevista, las personas participantes fueron informadas de los objetivos del estudio y firmaron un consentimiento informado en el que dejaban constancia de su voluntariedad y libertad de respuesta. Todas las y los profesionales a quienes solicitamos participar en la investigación accedieron a ser entrevistados.
} 
El origen del Trabajo Social como profesión de ayuda, de profundas y heredadas raíces judeocristinas que marcan el sentido originario del Trabajo Social, supone un elemento explicativo importante sobre las maneras de ejercer la profesión y relacionarse con los/as usuarias. El Trabajo Social, asociado a la asistencia al otro, se relaciona con una valorización del sacrificio personal y profesional cuya finalidad es posibilitar el bienestar de la ciudadanía. En términos simbólicos históricamente refiere al

«Carácter mesiánico de la profesión [y] la culpabilidad por no salvar al mundo y a las personas que se ayuda. Esto, unido al carácter vocacional que plantean algunos discursos dentro de la profesión misma, vinculado a un carácter voluntario o voluntarista» (Aranguren, 2014, p. 144).

Esta cuestión ha sido muy recurrente en las entrevistas realizadas, cuando hemos ahondado en su formación y la trayectoria profesional:

Como la mayoría de mi generación, y de las generaciones de hoy, según me dicen las alumnas de prácticas del centro, la vocación es lo que te mueve. Es el elemento central en la identidad de esta profesión. Ante todo has de sentir esa llamada de querer ayudar, de implicarte, de estar ahí por los demás, aunque sea sacrificado (E15).

En estos elementos de identificación profesional se reconocen las claves de reproducción y maternidad social (Perrot, 2008), que caracterizan las profesiones de ayuda, como la del Trabajo Social, en las que mayoritariamente se insertan las mujeres. Profesiones que tienden a identificarse con unas subjetividades y modelos de hacer; de trabajos de provisión y cuidado a los demás, que están en consonancia con los roles (personales y sociales) con los que se construye la identidad de género (Lamas, 1995). Son trabajos profesionales que suponen una prolongación del rol asignado tradicionalmente a las mujeres (Alcázar, 2014). «Al final mis usuarias son como mis hijas, mis hermanas, mis... algo, no lo sé, pero siento que he de protegerlas y que son responsabilidad mía. Por eso salgo a veces como una leona que defiende a sus crías» (E16).

No resulta así extraño que el Trabajo Social esté impregnado de valores, significados y representaciones femeninas asociadas con las capacidades y actitudes «naturalmente» atribuidas a las mujeres, basadas en un imaginario de sensibilidad, de protección, de capacidad de entendimiento y mediación, de preocupación por los demás y provisión de bienestar del resto de miembros de la unidad doméstica (Lorente, 2013). En el desempeño y sentido del Trabajo Social, el ser (profesional) para los otros (Lagarde, 1998) se construye en gran medida, y muy especialmente en la docencia, a partir de una noción central: la empatía.

A menudo, durante los años que pasamos en la Universidad, nos dijeron lo importante que era saber conectar con la persona, ponernos en su lugar y empatizar. Por otro [lado] te decían que si ... cuidado con la transferencia y la contratransferencia y perder la objetividad (...). Sin embargo, al menos en mi caso, pocas veces, o ninguna, oímos hablar de la delgada línea que separa una buena actitud para empatizar con la otra persona sin que tengamos que vivir la historia tan intensamente como si fuera nuestra (E4).

¿Qué ocurre cuando en el ejercicio de esa empatía afectiva empezamos a sentirnos afligidas, a manifestar ansiedad o incomodidad como respuesta al sufrimiento de la otra persona? (E5).

La empatía es la capacidad de sintonía emocional para comprender y ponernos en el lugar del otro, de la otra persona, para sentir lo que experimenta. Esta competencia, que continúa considerándose eminentemente femenina (Holgado, Delgado Egido, Carrasco Ortiz y Del Barrio Gandara, 2013) y explica los grados de implicación con respecto a las/os demás, es consustancial al aprendizaje y hacer del Trabajo Social, tanto en su dimensión cognitiva como metodológica. En consecuencia, el análisis de cómo aprendemos a empatizar desde el Trabajo Social no podemos desvincularlo del modo en el que se nos socializa, instruye (también en la Universidad) e interiorizamos el rol personal y pro- 
fesional de género, dado que nos aporta muchas claves para comprender la manera en la que las mujeres viven su ejercicio profesional. Igualmente, nos revela claves para analizar las formas en las que construimos los procesos de empatía y satisfacción de nuestro trabajo, así como de antipatía y rechazo. «Parece que si no te llevas el trabajo a casa o si no te implicas en todo lo que pasa en el barrio es que no eres una verdadera trabajadora social» $(\mathrm{E} 21)$.

Como consecuencia, en la investigación ha sido recurrente que las trabajadoras sociales se preguntaran si por el hecho de ser mujer, «¿hay situaciones y problemas en los que nos sentimos más próximas o distantes cuando a quien le afecta es a una mujer?» (E4). En los diálogos establecidos en las entrevistas se ha reflexionado sobre cómo razonamos y aplicamos determinados principios éticos profesionales, como el principio de autonomía y la manera en la que manejamos el reconocimiento de la capacidad de agencia de una mujer ante una situación de necesidad.

¿Sabemos cómo hacer efectivo el grado de respeto que debiéramos tener ante sus decisiones o nos emerge con más fuerza la (sobre)protección de la usuaria y/o la posible institucionalización de su situación? (E17)

¿Cómo puedo respetar la decisión de una persona que rechaza, por ejemplo, una intervención para tratar su dependencia al alcohol, cuando, desde mi punto de vista, esta patología determinada compromete la dinámica relacional de toda la familia, además de poner en peligro su salud? (E9).

¿Qué hacer en la intervención con familias cuyas costumbres culturales pasan por valorar la sumisión de la mujer al varón o conllevan prácticas como los matrimonios entre adolescentes, donde las chicas abandonan su formación para convertirse en esposas y madres? (E6).

Este tipo de dilemas son reiterativos, más aún cuando, al tener formación de género y feminismo en el Trabajo Social, emerge en ellas con fuerza el debate sobre cómo conciliar mi criterio profesional e ideológico con el camino elegido por la usuaria, con su libertad de fracasar: ¿Qué prioridad concedo, a mi juicio como trabajadora social, a realizar cambios en la situación de una mujer y a aquellos con los que - creo- va a obtener un mayor bienestar, a pesar de que ella no quiere realizarlos?, o ¿qué ocurre cuando como profesional soy capaz de analizar un problema desde una perspectiva de género, comprendiendo la globalidad de factores que dan lugar a una posición de subordinación de una usuaria, pero ella solo me demanda una intervención puntual, de beneficio a corto plazo que, sin embargo, reproduce su situación de desigualdad?

En nuestros primeros resultados de investigación hemos detectado cómo las mujeres, trabajadoras sociales, frente a un dilema de este tipo tienden a otorgar un peso central a la intuición, al «sentido común», a sustentarse en la ética de los cuidados y a la posibilidad de agencia de la mujer, valorando de forma más exhaustiva (que también conflictiva) los pros y contras de la toma de decisión. En las respuestas, los trabajadores sociales varones tienden a aludir constantemente a los derechos sociales y a la ética de la justicia social lo que, en principio, pudiera traducirse en menos autoconflictos, a la hora de solventar un problema que atañe a una mujerusuaria.

En definitiva, estas contradicciones permanentes reflejan los dilemas no resueltos entre nuestra formación en Trabajo Social, nuestras competencias éticas y la socialización e interiorización de género.

\subsection{Condicionantes en el ejercicio profe- sional con mujeres}

El ejercicio profesional se enmarca en un contexto institucional, administrativo, y espacial que, sin duda alguna, también determina el modo en el que acometemos la intervención, nos vinculamos con la(s) usuaria(s) y el peso que inferimos, o no, a la cuestión ética. En las distintas entrevistas se alude de forma insistente a los factores estructurales y espaciales como coartadores de una relación más fluida con las usuarias. La ubicación geográfica del centro de trabajo condiciona el acceso al servicio y el contacto, más o menos con- 
tinuo, y posibilita un seguimiento más regular o intermitente. A ello se le añade la disposición del mobiliario de la oficina, que transmite y viabiliza una relación más distante, de jerarquía, o de proximidad. El entorno físico e instrumental no siempre reúnen las condiciones para garantizar la confidencialidad y el clima de confianza, especialmente si tenemos en cuenta que una proporción muy significativa de los temas que se tratan son delicados y requieren discreción porque, como nos subrayan, o bien implican a menores o se refieren a situaciones de violencia física o sexual, o suelen conllevar una carga emocional importante por la angustia o vergüenza que las usuarias dicen sentir al tener que acudir para pedir ayuda institucional; o porque en ocasiones son situaciones controvertidas en las que se evidencia que la usuaria miente o no está dando toda la información, sea por proteger a una tercera persona sea por creer que omitir o falsear datos le favorece para obtener una prestación. Estos contextos dificultan la relación con la usuaria. Los despachos se comparten con varios profesionales, por lo que, además de un segundo profesional, puede haber otra usuaria o usuario que está siendo atendido en el mismo espacio. Todo ello condiciona inevitablemente la forma en la que se expresan y empatizan ambas partes.

El despacho tan masificado no ayuda a tener una confidencia o intimidad. Y menos aún las prisas y los protocolos de actuación que tenemos que aplicar, que son muy rígidos y automáticos... y eso genera distancia y frialdad (E20).

A estos factores ambientales, habitualmente invisibles por la resignación con la que se asumen, se añaden otros problemas, derivados del desplome de las partidas presupuestarias aplicadas a Servicios Sociales, que han supuesto una reducción de recursos humanos, materiales y económicos, justo en unos años en los que se ha incrementado el número de personas en situación de necesidad que acude a los centros. «A los (usuarios) de siempre se le añaden los que nunca hubieras imaginado antes porque era gente que vivía muy bien antes de la crisis») (E2). Se ha agudizado el desbordamiento de los servicios sociales públicos por la demanda creciente de atención social derivada de la crisis económica (VII Informe Foessa, 2014). Frente a este desequilibro, se repiten cada vez más los dilemas éticos relativos a cómo dar cobertura y distribuir recursos limitados entre las personas que tienen derecho al bienestar y las personas en situaciones de extrema necesidad. Al respecto nos manifiestan constantes sentimientos de frustración e impotencia.

Muchas de las nuevas usuarias son mujeres como yo, que ahora están en situación de necesidad extrema. Inevitablemente te implicas y te emociona. Te sientes comprometida, como trabajadora social y también como mujer (...) comprometida con una causa, que es mucho más que esa mujer que tienes delante (E14).

Es frustrante. No podemos llegar a todas las situaciones. Muchas de ellas son mujeres del barrio, que conoces de toda la vida, que son como tu familia extensa (...). Sientes que tienes la responsabilidad de ayudarlas porque son parte de tu vida (...). El dolor con el que se vive es tremendo (E1).

El nuevo perfil de usuarios y usuarias de Servicios Sociales se caracteriza por la feminización de las desigualdades, explicadas a partir de los mayores índices de pobreza y exclusión social de las mujeres en los tres principales ejes de integración: el mercado laboral, el Estado de Bienestar y las redes personales (Damonti, 2014). Estas situaciones se traducen en la sobrerrepresentación de las mujeres en la franja de la pobreza, debido a factores muy diversos condicionados por el género, como: el encabezamiento de las mujeres en hogares sin ingresos y con personas dependientes a su cargo; la prolongada exclusión de las mujeres de los circuitos formales del mercado de trabajo; o su inserción laboral de forma intermitente que les dificulta la cotización en la seguridad social para acceder a prestaciones contributivas (limitándose a prestaciones asistenciales). Incrementan las situaciones relacionadas con la violencia de género y su interrelación con otros procesos de exclusión (como la ausencia de ingresos económicos, de redes familiares, problemas de salud, exclusión de la vivienda o consumo de dro- 
gas). El retrato de las personas usuarias de Servicios Sociales tiene claramente rostro de mujer, de 36 a 50 años, con estudios primarios, sin ingresos económicos, muchas de las cuales antes eran de clase media (Consejo General de Trabajo Social, 2014). Sus demandas no son tanto de carácter individual como familiar, lo que evidencia que son ellas las interlocutoras con los Servicios Sociales y que la responsabilidad del cuidado sigue siendo cuestión de mujeres (Agrela, 2012).

En sus solicitudes lo que demandan están relacionado con la ayuda económica, la búsqueda de empleo, la información jurídica en casos de separación, la ayuda para manejar a sus hijos/as preadolescentes con problemas de conducta o las ayudas para atender a sus progenitores mayores (E10).

En su mayoría vienen porque son madres, abuelas o hijas (E18).

La sobrecarga de las profesionales del Trabajo Social está concentrándose en los servicios de información y valoración; intervención y apoyo familiar; e intervención y apoyo de menores (Lima, 2014). Consideran que la calidad de la atención y la respuesta está empeorando significativamente en los programas de atención a la pobreza o exclusión social y garantía de ingresos, y en la atención a la dependencia de personas mayores o en la discapacidad. Es decir, las necesidades son más acuciantes, precisamente en los ámbitos en los que las mujeres tienen una alta presencia, tanto por la carencia de recursos como por ser gestoras de los cuidados o titulares de la dependencia. «Hablar de dependencia es hablar de cuidados y es hablar de mujeres. Se mire por donde se mire. Y los recortes en este tema directamente son sobre las mujeres» (E6).

El incremento de personas usuarias se ve inversamente correspondido con el tiempo de atención que se les puede dedicar; hay menos profesionales contratadas/os y una mayor burocratización a la que se someten los expedientes. La complejidad y profusión de nuevas normativas y reglamentos de los procedimientos, que se modifican asiduamente debido a los recortes económicos y cambios políticos, requieren de una actualización permanente y un estudio continuado para su aplicación. «Tomemos como ejemplo el Programa de Refuerzo de Alimentación, que constantemente cambia» (E10). Este exceso de burocratización va en detrimento del tiempo de atención directa para «estar con la persona» (E8). El no tener las condiciones óptimas para personalizar adecuadamente la relación se traduce en una deshumanización de la relación con el usuario (Idareta y Ballestero, 2013), lo que genera numerosos dilemas sobre el tiempo de atención deseable para comprender el problema en su globalidad y cómo le afecta concretamente a las mujeres. Es una ecuación imposible de resolver en horario laboral, que tiende solucionarse a costa del uso del tiempo personal y familiar del trabajador o la trabajadora social, dificultando con ello las posibilidades de desconectar del trabajo. Esta práctica de «llevarse el trabajo y las emociones a casa» (E7) entronca con otro de los dilemas más habituales que dicen desbordarles: «¿soy mejor o peor profesional porque, cuando estoy en casa, empatizo o desempatizo con los problemas de mis usuarias?» (E9).

Entre los factores extrínsecos a la intervención profesional (Ballestero, Úriz y Viscarret, 2012), destacan los dilemas derivados de cómo conciliar la presión profesional con la presión institucional y la de las usuarias para resolver las necesidades más urgentes a la mayor celeridad posible. En los últimos años, los recortes de las políticas neoliberales han generado una indignación en la sociedad civil, que organizada como grupos de presión, como las «mareas» o el movimiento Stop Desahucios, irrumpen en el escenario político impactando también en el Trabajo Social. Sus protestas se agudizan con temas muy sensibles que atañen especialmente a las mujeres como: la vivienda, la violencia de género o los menores.

Han sido precisamente las mujeres, sobre todo las mayores, quienes en los últimos años han estado apoyando las reivindicaciones sociales. Reivindicaciones para ellas, vinculadas a sus necesidades relacionadas con su ciclo vital, pero muy especialmente relacionadas 
con su condición de madres y abuelas cuidadoras (E5).

Una parte muy significativa nos refiere, asimismo, a la intimidación ejercida por grupos políticos de la oposición que recriminan, en ocasiones, la actuación de las profesionales de Servicios Sociales. La información que transciende mediáticamente sobre su trabajo es habitual que esté muy distorsionada y no refleje adecuadamente la complejidad del trabajo técnico de la trabajadora y el trabajador social. «Cuando un caso salta a los medios todo se tergiversa, se simplifica, parece que tomamos las decisiones (de intervención) de forma aleatoria, sin formación... y eso te presiona y te cuestiona constantemente» (E13).

La incompetencia de otras y otros profesionales, que dificultan la gestión de una ayuda o la ausencia de colaboración interprofesional, son también dilemas centrales que se agravan en casos de emergencia como la violencia de género. "La intervención y la relación con la usuaria se hace muy dificultosa y no sabes cómo actuar» (E17). En ocasiones, se nos refiere a los dilemas originados por la inferencia de terceras personas, especialmente cuando son superiores, cuya intención es solicitar información sobre un expediente o intentar, con su «situación de poder», condicionar el tipo de respuesta otorgada a su demanda. También ocasiona profundos dilemas

Asistir a juicios en los que se tratan situaciones muy complejas, como por ejemplo, cuando se ha de decidir sobre la patria potestad de menores en situaciones con violencia de género y a eso se le añade ausencia de recursos económicos. A veces te debates entre el secreto profesional y el posible daño o beneficio que le pueda suponer a la usuaria (E6).

\subsection{Dilemas éticos sobre el ser y el deber ser}

Una de las principales dificultades manifestadas son los dilemas entre el ser y el deber ser ante los que los referentes deontológicos, las herramientas teóricas y los aprendizajes adquiridos de la experiencia profesional son insuficientes. Esto ocurre, especialmente como nos describen, cuando entran en conflicto los criterios de lo que me permite (o no) realizar la institución a la que represento y los juicios personales sobre cómo considero que pueden responder más adecuadamente al bienestar de la usuaria. Más aún cuando «el camino está fuera de la norma» (E11).

En consonancia con la investigación de Ballestero, Úriz y Viscarret (2012), hemos detectado que, cuando los dilemas se refieren a las situaciones de las mujeres, parecieran tener una dificultad particular añadida. Habitualmente los casos, que tienen por sujeto principal de intervención a las mujeres, requieren de un informe para terceros como, por ejemplo, para tramitar una ayuda económica a una cuidadora principal; para valorar cómo ejerce su maternidad y cuidado de los hijos o hijas a cargo, en casos de sospecha de una atención inadecuada - a menudo de mujeres que desempeñan el trabajo de (re)producción solas debido a que los progenitores se han marchado o desatienden a los hijos e hijas - en los casos de violencia de género; o en las solicitudes del Ingreso mínimo de solidaridad donde existe una complejidad mayor cuando se trata de hogares con una sola progenitora, que suele tener varios familiares dependientes a su cargo junto con una prolongada situación de desempleo. También son frecuentes expedientes de menores con informaciones previas abiertas por el Servicio de Protección de Menores y «cuyas madres se ven directamente involucradas» (E13); o cuando se solicita una plaza para la Escuela Hogar y se requiere información rigurosa sobre la persona que les tutela, que mayoritariamente son mujeres.

En el nuevo escenario de gestión de lo social, las funciones del Trabajo Social pasan cada vez más por la comprobación de las situaciones de necesidad de las usuarias. No se trata solo de estar en situación de pobreza y de carecer de recursos propios o en situación de dependencia y de que exista una falta de autonomía para valerse por sí misma, sino de poder demostrarlo y de que un informe lo reconozca como tal. «Ser beneficiaria» no es tanto una cuestión de reco- 
nocimiento de derechos sociales como de evidenciar ser más merecedora de una prestación o recurso que otra persona. Esto ha supuesto un incremento de tareas de control y comprobación de las nuevas formas de pobreza, que entraña mucho tiempo dedicado a tareas burocráticas, como la apertura de un expediente y su seguimiento; en muchos casos la continuidad de las prestaciones está condicionada a la demostración de un cambio de comportamiento, esfuerzo y responsabilidad de la persona (la mujer) por integrarse, de acuerdo con el modelo anglosajón de workfare que lo inspira: «Nos tenemos que encargar de comprobar cada semana de que la madre está cumpliendo lo acordado con los horarios, las comidas, las tareas de la casa...» (E1).

Para las trabajadoras sociales este modelo de gestión de la pobreza implica importantes dilemas con respecto al lugar en el que estas prestaciones ubican a las mujeres, como sospechosas habituales de que no ejercen bien su rol de cuidadoras o de que transgreden los modelos de género, femenino, esperados. Esto se traduce en una tutela constante sobre cómo ejercen su trabajo reproductivo: «tenemos que dar cuenta de cómo llevan la casa, en qué gastan el dinero, cómo educan o qué dan de comer a sus hijos/as»» (E18). Bajo este prisma, las usuarias tienden a ser estigmatizadas por la incapacidad que se les presupone para gestionar sus propias vidas y, como consecuencia, se aplican distintos mecanismos de control e intromisión sobre su vida personal. Tienden, por lo tanto, a ser objeto de acciones que las controlan y las reencauzan. Las profesionales, mujeres y varones entrevistados, son conscientes de las bondades de un Trabajo Social educativo y de cambio con determinadas usuarias, pero también les causa un dilema constante que ciertas prestaciones condicionadas están operando como mecanismos de domesticación y adoctrinamiento de determinadas conductas de las mujeres, en tanto cuidadoras de hogares. Presión que se ejerce igualmente a través de los discursos que estas prácticas entrañan, relativos a cómo se les culpabiliza solo a ellas de determinados problemas so- ciofamiliares que, en muchos casos, tienen que ver con las situaciones de exclusión en las que están envueltas. Esta domesticación de lo social (Donzelot, 1990) frecuentemente se elabora a partir de nociones de moralidad sobre cómo ser una buena madre e imponer un deber de responsabilidad con respecto a los otros.

En mi opinión, la autodeterminación es un principio de carácter básico. Es la puerta de entrada al conflicto personal entre el ser y el deber ser al que me enfrento casi a diario. En toda intervención profesional se ponen en contraste, al menos, tres fuentes de valores: los de la profesional, los de las personas o grupos con los que se interviene, o se quiere intervenir, y los propios de la entidad en la que se trabaja. Ello genera un conflicto de intereses, condimentado con, por una parte el desempeño de nuestra función de ayuda y, por otra de control social (E1).

Este tutelaje de las mujeres enlaza con la noción de violencia paternalista (Idareta, 2013), definida también como maternalista, centrada en hacer valer como fin último el bienestar de la usuaria por encima del procedimiento por el que se consiga y con independencia de su agencia y autonomía. Las metodologías y formas de participación en el proceso pasan a un segundo plano, asumiendo que la cliente no tiene capacidad para responsabilizarse de cómo resolver su problema. En el otro extremo, el dilema surge cuando se impone lo inverso, la violencia antipaternalista (Idareta 2013), ejercida cuando se prima el principio de autonomía de la usuaria, olvidándose del bienestar final. Estos modelos de intervención, analizados sobre todo en el contexto de salud mental, siguen siendo escasamente explorados en el ejercicio profesional del Trabajo Social con mujeres, a quienes ante determinados problemas se les tiende a «minorizar» y a tratar como a enfermas mentales, con capacidades limitadas y que no saben regirse por sí mismas. En un contexto tan burocratizado como el que se expone, se imponen intervenciones que a menudo dejan a las usuarias en los márgenes. El quehacer profesional se realiza mediante un protocolo que marca tiempos rápi- 
dos e impide dialogar, escuchar, contrastar versiones o aplicar metodologías más participativas para entender qué hay detrás de los discursos de las usuarias cuando plantean un problema o cuando toman una decisión que no comprendemos. «Hacemos un trabajo cada vez más individualizado en vez de elaborarlo a partir de grupos de supervisión y coordinación en equipo que posibilitarían una aproximación ética más acorde con la intervención» (E10).

Preocupa especialmente el modo como construimos significados de género a partir de los informes sociales, que además de una herramienta, debieran considerarse como enunciados discursivos que construyen la realidad, como narrativas argumentales de las que deriva la toma de decisiones. A menudo, nos insisten, se debaten entre qué aspectos enfatizar y cuáles no destacar demasiado, para que una tercera persona pueda interpretar el informe adecuadamente con una perspectiva género, evidenciando cómo por ser mujer su problema se agrava. Surge así el interesante debate sobre lo que se sabe, pero en ocasiones no se cuenta, en los informes «porque podría perjudicar a la mujer, pero ¿esto es ético?» (E4).

Los dilemas éticos que refieren a la autonomía de las mujeres, el derecho de autodeterminación y el principio del bienestar (Guillén, 1993; Salcedo, 2001) siguen siendo una preocupación recurrente. Se debe promover que elijan por ellas mismas, tomen sus propias decisiones y participen en las actuaciones que afectan a sus circunstancias, sean cuales sean sus valores y opciones de vida; pero las incertidumbres que se desprenden de ello se repiten constantemente:

¿Cómo hacerlo cuando se valora que las decisiones adoptadas por una mujer no están tomadas libremente, sino constreñidas por su pareja, por su condición de madre, o por la existencia de personas dependientes? (E14).

¿Qué hacer cuando una mujer toma una decisión sin tener en cuenta una información que nosotros sí tenemos con respecto terceras personas pero que, por el secreto profesional, no podemos desvelar? (E4).

\section{Debate abierto sobre los dilemas éticos, el género y las emociones en Trabajo Social}

El ejercicio del Trabajo Social implica numerosos dilemas éticos, relacionados con el género, así como una circulación de afectos que no está deslindada de la subjetividad con la que las mujeres construimos nuestra identidad profesional y modelos de hacer. Esto no es ajeno a la extensión del rol de género de «cuidado social», que hemos aprendido en la profesión y que condiciona los dilemas éticos. En el ejercicio profesional se generan múltiples emociones, fruto de los procesos de empatía, antipatía, transferencia o contratransferencia que inevitablemente acontecen. Frecuentemente nos debatimos entre el principio de autonomía de la usuaria, tratando de respetar su derecho a decidir (también a equivocarse), y la búsqueda de su bienestar último. El compromiso profesional y ético requiere un enfoque de género (y feminista) para revisar cómo incluimos los derechos de las mujeres en el Trabajo Social. A menudo, corremos el riesgo de caer en un maternalismo o paternalismo que olvida tomar en cuenta su capacidad de agencia en el proceso de intervención, al tiempo que menospreciamos los dilemas éticos y de género que nos asaltan. Incluir la ética con perspectiva de género en el Trabajo Social posibilitaría un cambio de mirada y de herramientas de intervención para hablar con ellas y no por ellas.

La profesión de Trabajo Social se realiza en una posición situada, encarnada y subjetiva también de género, con la que construimos el conocimiento para nuestra intervención. El desafío ético, tanto teórico como metodológico, pasa por incorporar las emociones y las contradicciones que tenemos en nuestro ejercicio profesional que, en aras de la supuesta objetividad y cientificidad del Trabajo Social, tradicionalmente han sido reprimidas y silenciadas. Resulta imprescindible entender los dilemas éticos y las emociones que nos provocan respecto a cómo vivenciamos nuestro trabajo, atravesado, entre otros factores, por los de género e identidad profesional. Inevitablemente, la cuestión ética en Trabajo Social nos obliga a hacer patente el ejercicio reflexivo de nuestra emocionalidad y debatir sobre ello. 


\section{Referencias bibliográficas}

Agrela Romero, B. (2012). Towards a model of externalisation and denationalisation of care? The role of female migrant care workers for dependent older people in Spain. European Journal of Social Work, 15(1), 45-61.

Alcázar Campos, A. (2014). Miradas feministas y/o de género al Trabajo Social, un análisis crítico. Portularia. Revista de Trabajo Social, 14(1), 27-34.

Amorós Puente, C. (dir.) (2002). Diez palabras clave sobre mujer. Estella: Verbo Divino.

Aranguren, E. (2014). Empoderamiento profesional e intelectual en Trabajo Social. Retos de futuro. Azarbe. Revista Internacional de Trabajo Social y Bienestar, 3, 139-147.

Ballestero Izquierdo, A., Úriz Pemán, M.J. y Viscarret Garro, J.J. (2012). Dilemas éticos de las trabajadoras y trabajadores sociales en España. Papers. Revista de Sociología, 4(97), 875-898.

Banks, S. (2006). Ethics and Values in Social Work. ( $3^{\mathrm{a}}$ ed.). Basingstoke: Palgrave.

Báñez Tello, T. (1997). Género y Trabajo Social. Acciones e Investigaciones Sociales, 6, 151-188.

Damonti, P. (2014). Una mirada de género a la exclusión social. En Fundación Foessa, VII Informe sobre exclusión social y desarrollo social en Andalucía y España (pp. 1-36). Madrid: Fundación Foessa y Cáritas Española.

Dominelli, L. y MacLeod, E. (1999). Trabajo Social feminista. Madrid: Cátedra.

Donzelot, J. (1990). La policía de las familias. Valencia: Pre-textos.

Fombuena Valero, J. (2006). La influencia de la dimensión de género en el Trabajo Social. Cuadernos de Trabajo Social, 19,133-154.

Fundación Foessa. (2014). VII Informe sobre exclusión social y desarrollo social en Andalucía y España. Madrid: Fundación Foessa y Cáritas Española.

Guillén Sádaba, E. (1993). La burocratización del Trabajo Social en Intervención Social. Cuadernos de Trabajo Social, 6, 181-193.

Holgado Tello, F., Delgado Egido, B., Carrasco Ortiz, M. y Del Barrio Gandara, M. (2013). Interpersonal Reactivity Index: Analysis of Invariance and Gender Differences in Spanish Youths. Child Psychiatry \& Human Development, 44(2), 320-333. doi: 10.1007/s10578-012-0327-9.

Idareta Goldaracena, F. (2013). Tras la estela de la responsabilidad ética. Origen y evolución histórico-filosófica de la ética del Trabajo Social hasta la actualidad. Cuadernos de Trabajo Social, 26(2), 489-498.

Idareta Goldaracena, F. y Ballestero Izquierdo, A. (2013). Ética, paternalismo y burocracia en Trabajo Social. Portularia. Revista de Trabajo Social, 13(1), 27-35.

Lagarde de los Ríos, M. (1998). Claves feministas para el poderío y la autonomía de las mujeres. Managua: Puntos de Encuentro.

Lamas, M. (1995). Cuerpo e identidad. En L. Arango, M. León y M. Viveros (comps.), Género e Identidad. Ensayos sobre lo femenino y lo masculino (pp. 62-82). Santafé de Bogotá: Ediciones Uniandes.

Lima Fernández, A. (2013). Organizaciones profesionales y deontología: plano nacional e internacional. En L.M. Rondón García y M.L. Taboada González (eds.), Voces para la ética del Trabajo Social en tiempos trémulos (pp. 106-126). Madrid: Ediciones Paraninfo y Consejo General de Trabajo Social.

Lima, A. (coord.) (2014). I Informe de los Servicios Sociales en España. Madrid: Colegio General de Trabajo Social.

Lorente Molina, B. (2013). Fundamentos para una teoría de la práctica ética en Trabajo Social: cuidado, justicia y división sexual de la acción social. En L. Rondón y M.L. Taboada (eds.), Voces para la ética del Trabajo Social en tiempos trémulos (pp. 29-46). Madrid: Paraninfo.

Morales Villena, A. (2010). Género, mujeres, Trabajo Social y sección femenina. Historia de una profesión feminizada y con vocación feminista. Granada: Universidad de Granada.

Ortí Mata, M. (2007). Introducción. La investigación sociológica en el ámbito del Trabajo Social. En F. Vallejos, M. Ortí e Y. Agudo, Métodos y técnicas de investigación social (pp. 9-14). Madrid: Centro de Investigaciones Ramón Areces.

Perrot, M. (2008). Historia de las mujeres. Madrid: Fondo de Cultura Económica de España.

Reamer, F. (1998). The evolution of Social Work Ethics. Social Work, 43(6), 488-500. doi: 10.1093/ sw/43.6.488. 
Red Europea de Lucha contra la Pobreza y la Exclusión Social. (2015). VInforme sobre El Estado de la Pobreza en España. Madrid: EAPN.

Rodríguez Fernández, C. (2014). Ética y Trabajo Social: La reflexión de la profesión, camino de ciudadanía. Azarbe: Internacional de Trabajo Social y Bienestar, 3, 55-61.

Salcedo Megales, D. (2001). Autonomía y bienestar: la ética del Trabajo Social (2 ${ }^{\mathrm{a}}$ ed.). Granada: Comares.

Salcedo Megales, D. (2015). El buen profesional. Cuadernos de Trabajo Social, 28(1), 19-26.

Úriz Pemán, M.J. (2013). Dilemas éticos en torno a los principios éticos básicos del Trabajo Social. En L. Rondón y M.L. Taboada (coords.), Voces para la ética del Trabajo Social en tiempos trémulos (pp. 194-209). Madrid: Paraninfo. 